\title{
A EXPERIÊNCIA SOCIAL DO TRABALHO \\ SOB A ÓTICA DAS FAMÍLIAS DOS \\ AGRICULTORES DA SELVA CENTRAL PERUANA
}

\author{
THE SOCIAL EXPERIENCE OF WORK FROM \\ THE PERSPECTIVE OF THE FAMILIES OF \\ THE FARMERS OF THE PERUVIAN CENTRAL JUNGLE
}

\author{
Ricardo Luiz Cruz
}

\section{Introdução}

0 interesse deste artigo em relacionar as trajetórias dos agricultores, de uma zona cafeicultora da selva central peruana, com as atividades remuneradas exercidas pelos seus filhos advém do fato de que, entre eles, seus trabalhos normalmente ganham sentido quando vistos em conjunto ${ }^{1}$. Em outras palavras, não que outros referenciais, para além dos laços entre pais e filhos, não sirvam de parâmetros para darem significado aos seus ofícios, como é o caso, em espe- cial, das suas vontades ou desejos individuais e de seus vínculos comunitários. Tensões entre esses pontos de vista costumam, inclusive, fazer parte do dia a dia destes sujeitos. Mas a questão é que as relações entre pais e filhos e as suas experiências diante do trabalho se confundem de modo a, muitas vezes, eclipsarem outros quadros de referência capazes de prover sentido a essa atividade. Este texto procura refletir a respeito da força social ou legitimidade dessa perspectiva familiar sobre o trabalho e, consequentemente, sobre sua prepon-

\footnotetext{
* Mestre e doutor pelo Programa de Pós-graduação em antropologia social do Museu Nacional/UFRJ. Atualmente realiza estágio pós-doutoral no Programa de Pós-Graduação em Ciências Sociais da Universidade Federal do Maranhão (São Luís/MA/Brasil). ricruz@uol.com.br

1. Klass Wortmann (1990), por exemplo, chama atenção para o fato de que, entre o que ele denomina de "sociedades camponesas", o trabalho não deve ser pensado separado da família. Ainda segundo esse autor, ambas as categorias (trabalho e família) não podem ser entendidas isoladas de outra que seria igualmente central para essas sociedades: a terra. Porém, essa categoria parece não assumir uma importância tão grande na reprodução social das famílias dos agricultores que vivem em regiões nas quais "a terra é plenamente alienável, sendo comprada e vendida com frequência” (MACFARLANE, 1989, p. 236). Essa tende a ser situação vigente em boa parte da selva central peruana, ou seja, a terra é aí vista, sobretudo, como um recurso econômico antes do que um patrimônio da família que carrega seu nome.
} 
derância diante de outros pontos de vista. Através dessa reflexão, também se estará discutindo o contato desses agentes com as transformações que perpassam não só suas vidas como as dos peruanos de um modo geral, na medida em que representam os personagens característicos do trabalho no Peru (de acordo, por exemplo, com os censos nacionais dos últimos trinta ou quarenta anos): o agricultor minifundista, o trabalhador informal e do setor de serviços e o micro ou pequeno empresário ${ }^{2}$.

Diante de uma situação economicamente desprivilegiada, como a vivida por grande parte das famílias dos cafeicultores da selva central, alguém interessado em compreender as experiências de seus membros com o trabalho pode ser tentado a concentrar sua atenção nas questões relativas à escassez e à distribuição desigual de recursos materiais vigentes entre eles ao longo do tempo. Sem querer excluir essas indagações do rol de preocupações do presente artigo, é importante ressaltar que seu interesse reside principalmente em compreender as dimensões sociais do trabalho de acordo com as próprias concepções que essas pessoas têm daquilo que aos seus olhos se mostra como o cerne de suas vidas sociais. Como ficará evidente no decorrer das próximas páginas, o trabalho e as relações familiares aparecem para esses sujeitos como o núcleo ou centro de suas existências. Ambos apresentam uma relativa autonomia diante do mundo econômico e, nessa autonomia, talvez resida uma das chaves para entender os sentidos dos seus esforços que, num contexto social mais amplo, isto é, para além das suas famílias, como, por exemplo, a economia nacional ou internacional, somente em algumas ocasiões (como nos anos 1970 e 1980, - quando os solos eram produtivos e os preços do café elevados) e/ou para uma parte deles (como os produtores com maiores cafezais e a minoria dos seus filhos que obteve um trabalho bem remunerado) foram recompensados, de acordo com suas visões.

Trata-se aqui, em outras palavras, de olhar para as distintas esferas sociais que perpassam as relações dessas pessoas com o trabalho, e não apenas para aquelas - como o Estado e o Capitalismo - normalmente dominantes numa perspectiva como a da economia política, a qual costuma acompanhar os estudos sobre camponeses ou pequenos e médios agricultores - como é o caso, por exemplo, do livro The Peasants of Eldorado do antropólogo norte-americano Robin Shoemaker (1981), uma das poucas pesquisas, de caráter etnográfico, que focaliza os cafeicultores da selva central peruana $^{3}$. 0 interesse principal dessa obra de Shoemaker é explicar a "estagnação" econômica vivida por esses sujeitos e sua tese é a de que a subordinação deles diante dos agentes que dominam a economia e a política do Peru impede a "acumulação local de poder econômico ou político”, isto é, inibe o "desenvolvimento regional" (idem, p. 37) ${ }^{4}$ Um dos méritos do autor é se apro-

2. As informações relativas aos censos nacionais peruanos podem ser encontradas em www.inei.gob.pe.

3. Uma crítica antropológica dos pressupostos da economia política pode ser encontrada em Ortner (2011).

4. Vale ressaltar que Shoemaker realizou seu trabalho de campo, na selva central, ao longo do ano de 1974, isto é, num período que precedeu um aumento substantivo no preço do café e que, conforme assinalado mais à frente, durou entre 1976 e o final da década de 80 . 
fundar na compreensão da centralidade do conflito entre a capital nacional e o interior do país para daí entender a dinâmica da sociedade peruana ${ }^{5}$. Porém, ele acaba não se preocupando com as visões que imperam nas famílias dos agricultores a respeito das dimensões sociais do trabalho. 0 presente texto, ao se perguntar por esse ponto de vista local, procura também questionar o olhar notadamente econômico de Shoemaker sobre os cafeicultores da selva central.

A narrativa que se segue tem como referencial principal minha pesquisa de campo entre as famílias dos agricultores associados a uma cooperativa da selva central: a La Florida ${ }^{6}$. Essa instituição é uma das pioneiras, entre as demais organizações de cafeicultores do Peru, nos mercados de café certificado como "orgânico" e no "comércio justo"7. Meu contato com seus sócios e funcionários teve início em 2005. Permaneci entre essas pessoas durante boa parte do ano seguinte e retornei à região onde vivem em 2014, quase oito anos depois desta última visita ao país.

\section{As condições sociais do trabalho como cafeicultor}

A partir da segunda metade da década de 1940, uma grande leva de pessoas co- meçou a deixar os Andes peruanos e a se dirigir, na sua maioria, para as cidades costeiras do Peru, em especial, à Lima, capital do país (CONTRERAS; CUETO, 2004). Dos anos 1960 em diante, um número menor, mas expressivo, desses migrantes, passou a se deslocar para as zonas amazônicas montanhosas, com destaque para a selva central. Os que foram até essa última região eram, em geral, jovens camponeses do sexo masculino, com cerca de 19 anos de idade, sem o primeiro grau completo e membros dos estratos mais baixos de suas comunidades de origem (BERG, 1984). Eles normalmente permaneceram lá trabalhando temporariamente como empregados na colheita de café, mas muitos acabaram tornando-se cafeicultores ao adquirirem uma propriedade - legalmente reconhecida ou não - nesse local ${ }^{8}$. 0 fluxo migratório até a região diminuiu desde os anos 1980, apesar dela continuar sendo um espaço alternativo para os que desejam abandonar momentaneamente ou de vez a cordilheira e viver por um tempo ou em definitivo num lugar que não a cidade de Lima, dado que, entre os "colonos andinos", vigora uma visão mais geral a respeito do deslocamento para a selva central como uma rota opcional disponível para os jovens, sem maiores recursos, interessados em deixar os Andes. Se-

5. "Lima emergiu como a sede do controle, o ápice administrativo da sociedade peruana. A partir disso, Lima sugou os recursos do interior e os apropriou para o seu próprio desenvolvimento econômico. Assim, hoje em dia Lima tem: bancos, hospitais, estradas, escolas, fábricas e muitas outras instalações e serviços. Este monopólio é um produto do sistema colonial interno do Peru.” (SHOEMAKER, 1981, p. 36).

6. Os membros ou "sócios" da cooperativa viviam no distrito de Perene ou no seu entorno. Perene esta localizado em Chanchamayo, uma das três "províncias" da selva central, ao lado de Satipo e Oxapampa.

7. 0 comércio justo é um mercado internacional organizado a partir de um ideal de solidariedade dos consumidores para com os "pequenos produtores", reunidos em cooperativas ou associações, e autorizados, através de um processo de "certificação", a participar desse sistema comercial.

8. Essa aquisição costuma se dar através da compra dessas propriedades ou por meio da ocupação de terrenos considerados "livres" e afastados das vias de comunicação. 
gundo um destes colonos: "quando jovem, uma professora me disse que quem tinha dinheiro deveria ir estudar em Lima e quem não tinha deveria ir trabalhar nos cafezais da selva central".

Não só nessa região, mas no Peru como um todo, o trabalho é uma atividade normalmente identificada com o universo masculino, conforme é possivel perceber através da leitura de dados referentes aos censos nacionais divulgados pelo Instituto Nacional de Estatística e Informática $(\mathrm{INEI})^{10}$. Os sucessivos censos têm, contudo, mostrado uma crescente participação das mulheres na "população economicamente ativa e ocupada" do país, em especial no ramo comercial. Entre os habitantes dos Andes contratados para trabalhar na colheita de café, as mulheres que os têm acompanhado são as esposas da minoria de homens casados existente entre eles. Elas, em geral, permanecem cuidando dos seus filhos e cozinhando para os trabalhadores da propriedade onde residem, apesar de, assim como as esposas e filhas dos produtores, também exercerem algum tipo de atividade agrícola, não na mesma intensidade que os homens, mas o suficiente para se afırmar que a lavoura não é um espaço associado a um só gênero - como é a cozinha, por exemplo. Ou seja, produzir café é uma atividade da qual homens e mulheres participam direta ou indiretamente.

As atividades realizadas no âmbito doméstico ou nas plantações podem ser vistas como "trabalho" na medida em que esta categoria ganha sentido entre essas pessoas, principalmente quando contraposta ao que definem como "ócio", isto é, ao lazer ou descanso nos horários destinados ao exercício do trabalho (as manhãs e tardes de segunda a sábado, em geral) e à diversão exagerada nos momentos de repouso para a prática posterior da atividade (as noites durante a semana e o domingo $)^{11}$. As crianças seriam ensinadas desde cedo a não serem "ociosas", como teria sido o caso dos filhos de uma cafeicultora que me contou que, "sempre que os via à toa", costumava derramar um pote de arroz no chão e, em seguida, os mandava recolher todos os grãos, para assim não se tornarem "vagabundos", segundo suas palavras.

0 trabalho temporário na colheita de café costuma ser feito pelos migrantes andinos nos períodos em que não se dedicam ao cultivo de batata. Esse tubérculo é o principal produto cultivado na cordilheira

9. É importante ressaltar que o êxodo rural andino, a partir da segunda metade da década de 1940, se deu num contexto de um crescimento demográfico, sem precedentes, nos Andes e de uma crise generalizada na agricultura desta região, por conta, em especial, da sua incapacidade ou dificuldade em competir com os produtos agrícolas estrangeiros que passaram a ser importados pelo país. 0 Estado peruano, inclusive, adotou uma série de políticas públicas, como a construção de estradas e a expropriação de latifúndios, por exemplo, em prol da colonização andina da selva enquanto uma espécie de "válvula de escape" para os conflitos agrários que permeavam diversas regiões dos Andes (CONTRERAS; CUETO, 2004).

10. Segundo o último censo nacional, 37,7\% das mulheres "economicamente ativas" do país se encontravam exercendo algum tipo de trabalho em 2007. Nesse mesmo ano, essa porcentagem, em relação aos homens, era de $71,2 \%$.

11. Na selva central, o lazer é o espaço, por excelência, do indivíduo e, nesse sentido, não é de se estranhar que ele se coloque como uma atividade institucionalizada ou regrada. No caso dos adultos, o divertimento se concentra no sábado à noite: esses são o dia e o horário em que podem consumir bebidas alcoólicas e se divertir sem se preocupar com o que os outros vão pensar. Isso porque, dizem, não irão trabalhar no dia seguinte e sim descansar e ficar com as respectivas famílias. 
e sua produção era sempre encarada pelos colonos como algo menos rentável para um pequeno agricultor do que a cafeicultura. Não é sem razão que conheci muitos deles que haviam deixado de plantar batata para produzir café, contudo, nunca escutei de ninguém qualquer menção a um desejo de largar a cafeicultura e se tornar um bataticultor. De qualquer maneira, a decisão de ir trabalhar na selva central era geralmente tomada como uma solução intermediária diante dos seus anseios de permanecer nos Andes (onde se sentiam mais seguros, mas carentes de fontes de renda) e o de se dirigir até Lima (lugar em que o "progresso" era mais aparente, mas onde alguém com escassos recursos econômicos, sem contatos locais e um maior grau de instrução difıcilmente poderia prosperar).

0 caráter limiar do trabalho nessa primeira região transparecia nas falas dos colonos ao se referirem ao seu deslocamento até esse espaço como uma “aventura”. Muitos, especialmente os que não se fixaram nele definitivamente, "viam sua carreira moral comprometida diante de seu ingresso num local dominado pelo passado e pelas forças rebeldes dos chunchos (indígenas amazônicos) indomados" (SARAH SKAR, 1994, p. 214). Já entre os que adquiriram mais terras e que possuíam uma maior familiaridade com a economia de mercado, esse cenário era encarado, de forma geral, enquanto "um lugar do futuro, uma fronteira aberta onde qualquer pessoa pode construir algo", e essa percepção foi, durante principalmente a década de 1960, enfati- zada pelas políticas governamentais (idem). É importante assinalar que as diferenças entre o tamanho dos terrenos em posse dos colonos eram, acima de tudo, explicadas por eles não com base nas suas diferenças econômicas, educacionais ou ideológicas, e sim na anterioridade do seu estabelecimento no local, ou seja, parecia normal para eles que "quem veio antes agarrou (ocupou) mais terra (que os demais)".

As grandes fazendas de café dominaram a paisagem da selva central até a década de 1960 e foram, até então, as principais responsáveis pelo emprego local dos trabalhadores originários dos Andes ${ }^{12}$. Diante do declínio político do latifúndio ao redor do país, nos anos 1960, os migrantes andinos começaram a dominar a posse da terra na selva central, fazendo com que sua economia passasse a girar em torno da produção de café em "pequenas" e "médias" propriedades, de acordo com a visão desses sujeitos. Esses colonos e seus descendentes formam hoje em dia a maior parte dos moradores locais. É comum se verem e serem vistos, pelos estudiosos dessa região, como "produtores" ou "agricultores" e não como "camponeses", ao contrário do que acontece em relação aos moradores das zonas rurais andinas (SANTOS; BARCLAY, 1995). Nestes últimos espaços, as trocas ou intercâmbios não monetarizados de trabalho se colocam como um mecanismo central na reprodução das relações comunitárias (MAYER, 2004) ${ }^{13}$. Já entre os migrantes residentes na selva central, a vida comunitária local é reduzida se comparada com a de suas

12. Os proprietários dessas fazendas eram, em geral, oriundos das regiões costeiras do país ou imigrantes advindos da Europa (SANTOS; BARCLAY, 1995).

13. Entre os camponeses que viviam nos Andes, é comum existir uma preocupação em ascender socialmente num espaço comunitário local, através da obtenção de "cargos”, cada vez mais prestigiados (e onerosos), nas festividades em torno de um santo padroeiro (OSSIO ACUÑA, 1992). 
terras natais, algo que Sarah Skar (1994) chama a atenção ao apontar o desinteresse e mesmo a aversão de alguns colonos em manter ou reforçar qualquer tipo de vínculo com seus vizinhos ${ }^{14}$.

É um consenso entre muitos estudiosos da vida social nos Andes, como é o caso, por exemplo, de Ronald Berg (1984), Marisol de la Cadena (2000) e Enrique Mayer (2004), a visão de que as comunidades rurais andinas têm na família nuclear, isto é, nas relações entre um casal e seus filhos, e não no indivíduo ou num grupo de descendência mais amplo, a sua unidade social básica ou central. As práticas e os discursos dos colonos andinos da selva central mostram que a família nuclear continua tendo uma importância capital nas suas vidas. Muitos, conforme já assinalado, migraram para a região ainda solteiros, mas quase que invariavelmente diziam que haviam deixado suas terras natais em busca de recursos que lhes permitiriam dar aos seus futuros filhos uma vida não pautada pelas privações e dificuldades que permearam suas infâncias e juventudes nos Andes ${ }^{15}$. Não é sem ra- zão que a selva central recebeu um número maior de colonos andinos nos períodos em que os preços internacionais do café dispararam, em especial entre os anos 1960 e o começo dos 1980 (SANTOS \& BARCLAY, 1995). Isso porque estavam interessados em garantir não só a "subsistência" de suas famílias (do contrário, muito provavelmente não necessitariam sair da cordilheira), mas também o acesso a bens que apenas poderiam conseguir através do mercado.

Uma minoria dos habitantes da selva central é composta pelos membros dos povos indígenas locais - os "nativos" ${ }^{16}$. A ocupação dos seus territórios pelas levas de colonos fez com que uma situação de conflito latente caracterizasse as relações entre esses dois grupos étnicos. Os migrantes e seus filhos costumam justificar as desigualdades locais com a ideia de que "é o trabalho árduo" que faz com que alguém "progrida na vida" (ocupe uma posição moral e material superior), um comportamento que, segundo eles, estaria notadamente ausente nos indígenas ${ }^{17}$. Conforme já assinalado, a dicotomia entre trabalho e ócio é central na visão

14. A emergência de sentimentos ou vínculos comunitários, nos espaços ocupados pelos colonos andinos, se dava, sobretudo, nas suas lutas/mobilizações políticas (mais intensas no passado do que no presente), nos seus pertencimentos às cooperativas, durante as celebrações locais (como as festas dos santos padroeiros dos povoados, por exemplo) e nos seus contatos com as escolas onde seus filhos estudavam. Eram através desses contextos/situações que afloravam ou eram alimentados os desejos desses migrantes e de seus filhos serem (ou se verem) reconhecidos aos olhos de outras pessoas locais fora de suas famílias. De qualquer maneira, a vida comunitária entre eles não era institucionalizada, pelo menos se comparada com a vida comunitária nos Andes organizada em torno do chamado ayllu.

15. Carlos Degregori (1990) afirma que, com a expansão do mercado e do Estado às zonas rurais andinas, no século XX, "uma porcentagem crescente das populações andinas deixou de olhar para o passado, de esperar a volta do Inca, tal como propunha o clássico mito de Inkarri, e se laçou com uma vitalidade insuspeita à conquista do futuro. E aí, em um ponto neurálgico, se localiza a escola.” (idem, p. 48).

16. Segundo Santos \&t Barclay (1995), 20.9\% da população rural da selva central é formada ou composta por membros dos povos indígenas locais.

17. Nas minhas conversas, de caráter mais privado, com os indígenas ou com os colonos, não era raro escutá-los acusarem as pessoas do outro grupo étnico de apresentarem um comportamento amoral, entretanto, dificilmente os dissociavam da esfera da humanidade. As acusações dos primeiros envolviam, em especial, uma visão que valorizava a "simbiose" ou "reciprocidade" entre os humanos e a natureza, 
dos colonos sobre o trabalho e, no entender desses sujeitos, quem se dedica com afinco a essa atividade é digno de respeito e admiração $0^{18}$. Todavia, tanto eles quanto os indígenas enfatizavam seus comprometimentos com o trabalho em suas falas, como, por exemplo, quando criticavam quem "ficava jogando conversa fora”, e essa visão crítica parecia se refletir no desconforto de alguns em serem vistos comigo ${ }^{19}$.

$\mathrm{Na}$ selva central, em se tratando das terras concedidas e/ou tituladas pelo poder público, as de menor aptidão para a agricultura, em especial, as que apresentavam um elevado declive e as mais distantes das vias de comunicação, acabaram ficando com os índios e não com os colonos (idem). Por detrás dessa distribuição desigual da terra em benefício dos migrantes andinos, esteve notadamente presente a visão adotada por estes e também pelo Estado peruano a respeito de um suposto caráter "não produtivo" dos povos amazônicos. A difusão da agricultura comercial entre os indígenas se colocou não só como um meio para obterem recursos monetários, como também enquanto uma estratégia defensiva, tendo em vista a manutenção de seus territórios diante do avanço dos colonos, apesar de, em geral e ao contrario dos migrantes andinos, "dedicarem mais tempo às atividades de subsistência do que à produção mercantil" (SANTOS, 2004, p. 242) ${ }^{20}$. Porém, o cultivo de café entre as comunidades indigenas "criou um certo nivel de diferenciação socioeconômica interna, a qual restringe o âmbito das relações de reciprocidade e com isso as bases da solidariedade intracomunitária" (SANTOS; BARCLAY, 1995, p. 305 $)^{21}$. Uma jovem indígena me explicou da seguinte maneira o fato de seu pai e outros dois indigenas que viviam ao seu redor serem os únicos nativos de sua localidade que possuiam veículos: "eles escolheram trabalhar, tem gente que tem terra e não quer trabalhar, não quer ter mais". Por outro lado, os três pertenciam às famílias extensas identificadas com o povoamento inicial do território local, e era comum essas famílias "fundadoras" terem maiores extensões de terra.

A importância dada pelos índios à família nuclear e que se manifesta, em especial, nas suas recorrentes e angustiadas preocupações com o "futuro de seus filhos", não deixa de estar relacionada com a maneira violenta como se deu a difusão local da agricultura comercial, dado que, por um lado, envolveu a expropriação de seus territórios e, por outro, impôs a necessidade de adotarem uma disposição em relação ao tempo (acumular bens e dinheiro) es-

um ideal que não seria compartilhado pelos migrantes andinos. Não era à toa que costumavam criticá-los por estarem, no seu entender, "acabando com o meio ambiente". Segundo me contou um indígena local, "os colonos acabaram com os animais (silvestres) e com as plantas medicinais." Talvez não seja exagero afırmar que a colonização andina envolveu aquilo que Pierre Clastres (2004) chama de um "etnocídio" ("destruição cultural") dos povos amazônicos, no caso, da selva central.

18. De acordo com Juan Ossio Acuña (1992), a valorização do trabalho e a condenação do ócio ocupam uma posição central no universo cultural andino desde o período pré-hispânico.

19. Shoemaker (1981) relata ter percebido esse desconforto durante seu trabalho de campo na selva central. 20. A mandioca é o principal cultivo de subsistência presente entre os indígenas.

21. "Esta diferenciação se expressa na posse de um número maior de bens manufaturados, incluindo bens suntuosos para os padrões locais; no aprimoramento da infraestrutura produtiva, como a compra de caminhões, e na ampliação de atividades mercantis, através da abertura de mercearias, mas também, por exemplo, em maiores oportunidades de educação para os filhos." (SANTOS-GRANERO, 2004, p. 243). 
tranha aos seus costumes ${ }^{22}$. Eles se viram obrigados a adotar um padrão de comportamento em torno do trabalho que, por um lado, impedia ou dificultava a manutenção de vínculos para além da família nuclear e os quais, por outro lado, eles valorizavam muito. Todavia, o descompasso entre a necessidade de acumulação e as condições objetivas de sua realização igualmente se colocava como um problema para grande parte deles. Essa situação também permeava a vida de muitos colonos e, tal como entre os indígenas, suas trajetórias eram vistas como intrinsecamente ligadas às de seus filhos. Os "sacrifícios" feitos em prol de seus descendentes e expressos na linguagem, por excelência, da vida social andina - o trabalho - ao mesmo tempo em que conferiam sentido aos seus esforços, eram contados aos seus filhos e presenciados por eles, e parecem assim ter sido fundamentais para a criação de um sentimento de dívida, isto é, de um laço ou uma ligação que, interiorizados, passaram a fazer parte de sua visão de mundo ${ }^{23}$.

\section{Trabalho e Família}

A Cooperativa La Florida foi criada em 1966 por um grupo de colonos advindos dos mais variados lugares dos Andes. Tais migrantes, considerados os "fundadores" da cooperativa, haviam se estabelecido, a partir de 1960, num relativamente amplo território da selva central ${ }^{24}$. Trata-se de um espaço que, por uma decisão do Governo nacional da época, deixou de pertencer a uma companhia estrangeira que nele plantava café de maneira incipiente. Sua expropriação fora reivindicada através de uma intensa mobilização desses colonos e de outros migrantes andinos que, como eles, também eram trabalhadores dos cafezais da região. Eles e o próprio poder público usaram como justificativa para essa desapropriação o suposto uso "especulativo" e, consequentemente, "não produtivo" do território por parte da companhia estrangeira. 0 local era e ainda é habitado por comunidades indígenas amazônicas das etnias Yanesha e Ashaninka, cujos membros trabalharam ou não nos cafezais dessa empresa e mantiveram e/ou mantêm relações mais ou menos amistosas com os colonos. A luta pela desapropriação uniu estes últimos e uma pequena parte dos índios locais numa espécie de comunidade que está por trás da fundação da cooperativa e que continua vigente até os dias de hoje, apesar das visões mutuamente depreciativas que costumam caracterizar as relações entre esses dois grupos étnicos ${ }^{25}$.

22. Uma indigena, comentando comigo suas apreensões em relação ao "futuro de seus filhos", afirmou que seus pequenos cafezais não lhe proporcionavam o dinheiro suficiente para arcar com os gastos em torno do material escolar e do uniforme destes últimos, sendo que um deles fora advertido pela sua professora (a única indígena com diploma de ensino superior no âmbito local) de que não poderia continuar frequentando a escola sem sapatos (algo cujo valor destoava da renda de seus pais).

23. Por exemplo, um filho de colonos escreveu, na sua página eletrônica de uma reconhecida rede social da internet, a seguinte mensagem para sua mãe: "hoje é aniversário da minha mãe, uma mulher lutadora, trabalhadora e muito atenta com seus filhos, obrigado por tudo que pode me dar".

24. Atualmente, boa parte dos produtores associados à cooperativa é formada por esses ditos fundadores, pelos seus filhos, pelos migrantes que trabalharam em suas terras e pelos filhos desses "ex-trabalhadores". 25. A Cooperativa La Florida tinha cerca de 1.200 sócios em 2005/2006 e também em 2014. 
Os conflitos nos quais se envolveram, para conseguir com que essa área fosse desapropriada, eram frequentemente revividos nos discursos que os migrantes, que participaram desses confrontos, faziam a respeito de suas trajetórias na selva central. 0 mesmo valia em relação aos seus esforços e sacrifícios iniciais como produtores de café desprovidos de maiores recursos monetários e situados numa região que na época não possuía praticamente qualquer infraestrutura (como estradas, escolas, lojas e hospitais). Tais discursos tinham como contraponto a trajetória dos colonos que vieram depois deles, trabalharam nos seus cafezais e receberam em troca uma porção dos seus terrenos ou compraram parte dos mesmos. Eram como narrativas que procuram legitimar o fato de que os "mais antigos", ou "fundadores" das localidades onde vivem os migrantes, através da divisão entre si do território expropriado da companhia estrangeira, dominaram a posse das terras localizadas nesse espaço mais amplo. Mas eles também buscavam enfatizar ou destacar, perante os filhos desses agricultores, o quanto seus pais se sacrificaram para que pudessem ter um lugar para plantar ou outros recursos necessários para que fossem capazes de "progredir na vida".

Conforme dito anteriormente, nesse plano local, os agricultores eram considerados, dependendo do tamanho de suas propriedades, como "medianos" (geralmente os "mais antigos" que não tiveram que dividir suas terras com seus filhos) ou "pequenos" (os demais cafeicultores), isto é, não existia a figura do grande produtor. Nesse cenário e em muitos outros espalhados pelo Peru, as relações de poder baseadas na posse desigual da terra (como a divisão do trabalho entre proprietários e trabalhadores, por exemplo) eram menos explícitas do que as que eram frequentemente encontradas no país antes da reforma agrária de 1969 , quando o latifúndio dominava a agricultura peruana. Não é à toa que as diferenças entre dominantes e dominados se mostrem mais sutis hoje em dia em boa parte do universo rural nacional. De qualquer maneira, entre os indígenas da selva central, era comum alguém apontar para as relações de força por trás do avanço dos colonos sobre seus territórios.

Não podemos entender a perda da autonomia do modo de vida tradicional dos indígenas locais sem levar em conta o fato de morarem hoje em dia em espaços chamados de "comunidades nativas", cujo tamanho extremamente reduzido, do ponto de vista dessas próprias pessoas, impede que tenham uma vida semelhante à dos seus antepassados, os quais dispunham de um amplo território para reproduzirem seus costumes - como era o caso da caça regular de animais silvestres, hoje bastante escassos na região. Além disso, com o crescimento vegetativo das comunidades nativas, os índios acabam dispondo de cada vez menos terra em relação ao seu contingente populacional. Segundo o estudo de uma organização não governamental que auxilia os moradores locais, apesar da pobreza ser endêmica entre essas pessoas, sua incidência entre os indígenas é "mais aguda" do que entre os colonos (DESCO, 2005). Para entender as condições por trás do atual tamanho dessas comunidades, é preciso retroceder ao início da década de 1960, época em que, como já assinalado, o território onde se encontram deixou de pertencer a uma companhia estrangeira e foi distribuído, com base numa autorização do poder público, entre uma minoria de indígenas amazônicos e um contingente maior de colonos andinos. 
Apesar dos índios compartilharem hoje em dia com os migrantes desejos tão caros, como o de ver seus filhos "seguindo adiante" nos estudos e "progredindo na vida" até se tornarem "profissionais", e também comungarem com eles o interesse no "desenvolvimento" da cooperativa, suas trajetórias eram não só distintas como marcadas pelo desencontro no modo de percebê-las, dado que um grupo nutria pelo outro uma visão depreciativa: para os índios, os colonos eram, notadamente, "gananciosos" e, para estes, aqueles eram, sobretudo, "ociosos”. Ambos reconheciam que os migrantes tinham, em geral, uma condição de vida melhor do que a dos nativos. Para os indígenas, essa disparidade residia principalmente numa distribuição desigual da posse da terra. Diziam que seus esforços na produção de café não eram recompensados da mesma forma que os dos colonos porque possuíam propriedades menores do que esses em se tratando dos locais onde podiam plantar o grão.

De qualquer maneira, os dois grupos compartilhavam uma mesma expectativa de melhoria das suas condições de vida. Os que, na visão local, "investiram" seus recursos na educação de seus filhos, como, por exemplo, construindo uma residência numa cidade onde estes, "por conta dessa casa, foram capazes de frequentar uma faculdade”, se destacavam perante os que, segundo diziam, teriam privilegiado a compra de um veículo ou pedaço de terra para seus descendentes trabalharem como motoristas ou agricultores. Já os que supostamente "gastaram" uma parte "excessiva" de suas economias em "festas" (de aniversário, em especial) e/ou no consumo de "bebidas" (alcoólicas), eram vistos com bastante desprezo.

Alguns colonos "mais antigos" compraram um terreno na zona rural local e/ou um automóvel ou caminhão com base, segundo eles próprios diziam, no dinheiro obtido com a venda de café, durante os anos de 1970 e 1980, quando a produtividade natural do solo e o preço do grão eram bastante altos. Um número ainda mais reduzido dos migrantes teria usado esse dinheiro para criar as condições que permitiram aos seus filhos ingressar no Ensino Superior ${ }^{26}$. Contudo, era bastante rara a existência de um indígena que houvesse conquistado qualquer um desses "objetivos - a aquisição de um terreno ou veículo e ter um filho que cursou uma faculdade. No imaginário dos colonos, os nativos eram comumente associados à utilização indevida de suas economias em atividades ligadas ao que definiam como “diversão”. Ou seja, eles não só trabalhariam pouco como também não saberiam como usar seus escassos recursos. Essa visão depreciativa procurava dar con-

26. Conversando com alguns dos filhos desses colonos, escutei deles que seus pais se diferenciavam dos demais cafeicultores locais, entre outras coisas, por serem filhos de fazendeiros ou de alguém com uma posição social superior aos pais deles, por trabalharem com o comércio e não apenas com a agricultura (como era o caso, em especial, de suas mães que possuiam uma pequena loja de secos e molhados nas suas respectivas chacras) e por terem um maior grau de instrução. De qualquer maneira, seus pais não gostavam ou não se interessavam em falar de suas diferenças sociais em relação aos demais produtores, preferindo ressaltar ou se concentrar, durante seus relatos autobiográficos, nos seus esforços e sacrifícios enquanto trabalhadores rurais ou cafeicultores na selva central. Porém, esses filhos dos colonos se pensavam como um grupo socialmente distinto nesse plano local. Eles foram e continuam sendo meus principais interlocutores entre os habitantes da selva central. Eram como sujeitos "híbridos" situados entre um universo rural e uma emergente classe média urbana de ascendência andina. 
ta das disparidades entre os dois grupos, mas deixava de lado qualquer consideração a respeito do acesso desigual à terra.

Outros atores também permeavam o cenário local. Um contingente importante era o dos "peões", isto é, dos trabalhadores (sazonais ou não) empregados nos cafezais, sejam os de origem andina ou amazônica. Era comum, entre os colonos que lá residiam, ter sido funcionário de alguém também advindo dos Andes, na medida em que trabalhar num cafezal alheio era um primeiro passo para os migrantes se estabelecerem na selva enquanto cafeicultores. Entretanto, ser empregado por outrem era sempre considerado uma posição subalterna perante os proprietários. 0 fato dos indígenas, por conta da sua escassez de terra própria para o cultivo de café, terem que vender regularmente sua força de trabalho, numa proporção maior do que entre os agricultores andinos, reforçava sua condição inferior diante desse grupo étnico. Contudo, a incorporação, pelos índios, de um ideário que valorizava as relações de interdependência entre trabalho e família, para além de envolver uma situação de "dominação cultural" diante dos colonos, também era capaz de fornecer uma matriz de significados para seus esforços, ou seja, seus trabalhos podiam ser economicamente pouco reconhecidos ou prestigiados, mas, assim como se dava com boa parte dos moradores locais que, segundo se dizia, "tratava apenas de sobreviver”, essas atividades ganhavam um sentido maior ao serem associadas com o passado ou o futuro de seus familiares.

Os demais personagens que compunham a paisagem dessa zona rural, como era o caso dos professores das escolas locais e dos técnicos das cooperativas que assessoravam os produtores, por exemplo, apesar de possuírem propriedades onde cultivavam café, eram sempre identificados pelos moradores da região mais em relação a essas atividades do que como cafeicultores. Por trás do reconhecimento destes "profissionais" estava presente um ideário de ascensão social cujo cume era situado na obtenção de uma "profissão". 0 fato da "educação" se colocar como um meio privilegiado para se ascender socialmente transparece claramente nas entrevistas feitas com os moradores locais pelos membros de uma já citada organização não governamental presente entre eles quando os conheci:

Tanto as mulheres quanto os homens consideram que a educação é muito importante. As razões que dão são as seguintes: "serve para o futuro", "permite uma formação pessoal" e "nos ajuda a nos realizar e a progredir". Especificamente, os homens afirmavam que "melhora a atitude das pessoas", "permite desenvolver melhor a vida" e "permite responder melhor às oportunidades que se apresentam” (DESC0, 2005, p. 369).

Não podemos deixar de levar em conta, se quisermos entender a construção social de uma noção local de ascensão social, o fato de que, em geral, as propriedades familiares vão sendo dividas de uma geração a outra e seus solos e plantações são cada vez mais improdutivos. Lembro o caso de um colono "mais antigo" que dividiu suas terras com seus filhos, na medida em que estes, de acordo com este senhor, não só não “avançaram” em seus estudos como não conseguiram encontrar um emprego “decente". Um destes filhos me disse o seguinte: "Não nos educamos bem, havia a possibilidade; agora se sabe que tem que ser competitivo. Antes a ambição era produzir muito café e ter coisas". Ainda segundo ele, na época que em os preços eram altos (entre 1976 e 1989), "poucos investiram 
na educação, (...) se o preço baixava, era por pouco tempo. Se achava que era muito melhor o filho ficar no cultivo de café".

A visão da cafeicultura como uma atividade em decadência persiste nesse ambiente rural, apesar dos esforços dos produtores e de sua destacada e reconhecida cooperativa em amenizar os efeitos dessa crise entre eles, em especial, através da venda de seus cafés pelo sistema de comércio justo e certificados como "orgânicos"27. Entretanto, suas atuais dificuldades produtivas fazem com que se beneficiem bem menos do que antes em relação a uma melhora no valor que recebem pelo grão. De acordo com um produtor local, "anteriormente se colhia 30 a 40 quintais (cada quintal tem $46 \mathrm{~kg}$ de café) por hectare, com três hectares se vivia bem e poucos se esforçavam para ter mais hectares.” Ainda segundo ele, “antes, nessa zona, um pequeno produtor produzia de 100 a 150 quintais e um mediano 800 quintais. Agora, os pequenos produzem entre 10 a 20 quintais e os medianos de 80 a 100 quintais".

Em 2005, por exemplo, a cooperativa aqui destacada pode, através da venda dos cafés de seus associados pelo comércio justo, pagar a eles cerca de US\$ 125 por quintal. No ano de 2013, ela foi capaz de remunerá-los, em média, com US\$ 170 por quintal. Nas décadas de 1970 e 1980, esses produtores chegaram a vender essa mesma quan- tidade do grão por US\$ 300 (CRUZ, 2010). Não era à toa a posição de destaque dada às famílias que conseguiam ter uma fonte de renda fora da cafeicultura, ainda mais se fosse por meio de um emprego bem remunerado conduzido por um ou mais de seus membros, como, por exemplo, o trabalho como dentista, advogado ou engenheiro. Mas eram poucos os filhos dos agricultores com diploma universitário e que exerciam essas profissões ou qualquer outra típica das classes mais abastadas do país ${ }^{28}$.

Uma boa parte dos jovens locais continuava trabalhando nas terras de seus pais e nelas construíam suas famílias ${ }^{29}$. Dificilmente, suas rendas mensais, com base apenas no dinheiro que obtinham com a venda de seus cafés, excedia um salário mínimo (cerca de US\$ 138 no ano de 2005 e do dobro disso em 2014), chegando, em média, a um pouco mais da metade dessa remuneração. Aqueles que dividiam o trabalho na lavoura com o de "mototaxista" num povoado ou cidade da região - geralmente jovens, solteiros, com entre 18 e 25 anos e sem ensino superior - poderiam conseguir até um salário mínimo por mês com esta última atividade, mas apenas se utilizassem um veículo próprio e não o alugassem de outra pessoa. Esse mesmo valor recebiam as filhas dos cafeicultores - normalmente com a mesma idade e grau de instrução dos mototaxistas - que eram empregadas no

27. Tal clima de decadência local foi expresso da seguinte maneira por um produtor "mais antigo": "antigamente havia boa colheita e bons preços, agora as chacras estão velhas como nós".

28. Por exemplo: dos 24 alunos que concluíram o Segundo Grau num colégio local, em 1984, somente cinco deles ingressaram no Ensino Superior. Dos também 24 alunos que concluíram o Segundo-Grau num outro colégio da região, em 2006, apenas seis deles prosseguiram com seus estudos, em especial através do ingresso nos "institutos superiores" existentes na selva central. Comparando esses dados com os fornecidos pelos últimos censos nacionais, é possível afirmar que esses dois exemplos são bastante representativos em relação à realidade da educação nesse plano local.

29. De acordo com o censo de 2012, em Perene, distrito onde vivia a esmagadora maioria dos sócios da Cooperativa La Florida, 35\% dos agricultores havia recebido seus terrenos através de herança. 
setor de serviços e no comércio local, notadamente, nas lojas e restaurantes das zonas urbanas $^{30}$. Outro trabalho comum, fora das chacras, entre os descendentes dos agricultores, era o exercido pelos seus filhos, especialmente os casados e com mais de 35 anos, que transportavam os moradores em seus automóveis ou nos de terceiros (no caso dos que trabalhavam em seus próprios veículos, esse emprego rendia cerca de três salários mínimos).

Muitos também se dirigiam à capital do Peru (ou outra cidade costeira ou andina) e lá exerciam algum tipo de trabalho que poderia ser classificado como "informal", "temporário" ou "precário", e que lhes proporcionava uma renda que dificilmente excedia o valor de três salários mínimos ${ }^{31}$. A questão é que o deslocamento para fora da selva central, assim como ser dono de um veículo ou trabalhar na loja de um parente, por exemplo, envolvia, em boa medida, a posse de determinadas disposições e capitais - econômicos, culturais e sociais - que lhes foram incutidos ou outorgados através de seus pais, ou seja, habilidades, recursos monetários, um grau de instrução e/ou rede de relações, todos possuídos numa propor- ção relativamente elevada para os padrões locais. Trata-se de uma região onde, de acordo com o último censo, a renda familiar per capital mensal é um terço do salário mínimo, e esse valor parece refletir o peso do trabalho agrícola mal remunerado na sua economia. Não mais do que $20 \%$ dos cafeicultores produziria uma quantidade de café (100 quintais) que muitos consideravam como "satisfatória" e os tornava "sustentáveis"32. Tal produção, em tese, deveria lhes proporcionar uma renda mensal de três salários mínimos.

Em 2014, cerca de 20 filhos de produtores ligados à Cooperativa La Florida (vale lembrar essa entidade tinha, nesse ano, ao redor de 1.200 agricultores associados) exerciam um papel de destaque na intermediação das relações dos cafeicultores com o comércio justo e/ou outros mercados de café também recentemente criados e em voga. Os primeiros ganhavam em torno de 15 a 20 salários mínimos por mês (com um deles, chegando a ganhar o triplo desses valores) ${ }^{33}$. Eles eram, em geral, gerentes das organizações de produtores e/ou comercializavam café "por conta própria" ${ }^{34}$. Começaram suas carreiras ligados à cooperativa

30. Grande parte era empregada nas lojas ou restaurantes de seus pais, tios ou parentes mais distantes.

31. 0 fato dos filhos dos cafeicultores terem migrado para Lima (ou para outra cidade qualquer fora da selva central) não tem implicado, como será discutido adiante, numa descontinuidade radical entre suas vidas e as de seus pais. Vários retornam não só para visitá-los como para cuidar de suas propriedades rurais numa espécie de rodizio feito entre eles e seus irmãos ao longo dos anos.

32. Tal proporção de "agricultores sustentáveis" ou de "médios produtores" era estimada pelos funcionários de distintas cooperativas locais com as quais entrei em contato.

33. Esse sujeito deixou de lado seu emprego na Cooperativa La Florida para se dedicar a uma então pequena empresa que havia criado há pouco tempo e através da qual passou a comercializar uma grande quantidade de café dos membros de outras cooperativas.

34. 0 cargo de gerente de uma cooperativa era o mais prestigiado e melhor remunerado entre todos aqueles ligados às organizações de produtores de café. Porém, o “comércio privado” ou “por conta própria” passou a ser mais valorizado pelos gerentes das cooperativas do que o trabalho nestas entidades, na medida em que através dele conseguissem obter "mais dinheiro para suas famílias", apesar de não ser normalmente bem visto pelos agricultores de um modo geral. 
de seus pais, a La Florida, e através dela puderam entrar em contato ou trabalhar com diferentes cooperativas existentes não só na selva central como em outras localidades espalhadas pelo Peru. Compartilhavam certas propriedades sociais (como um grau de instrução elevado para os padrões locais e a relação direta com uma cooperativa pioneira entre as demais do país na inserção nos novos mercados de café) que lhes conferiam as condições privilegiadas para ocupar essa posição de mediadores ${ }^{35}$. Também haviam incorporado determinadas disposições que fizeram com que encarassem o papel de mediação entre os cafeicultores e os novos mercados de café como uma espécie de vocação profissional ou compromisso de vida. Não era sem razão que formaram um contingente de pessoas que foi atuante e expressivo dentro do movimento nacional dos produtores desse grão.

Tais propriedades sociais e disposições remetem à história coletiva protagonizada por seus pais desde que estes se estabeleceram na selva central após deixarem os Andes. Em certo sentido, a geração mais jovem dava continuidade às "sagas" destes agricultores ao conectá-los com o que havia de mais moderno em matéria de comércio de café. Contudo, esse papel de mediadores os diferenciava da maior parte dos filhos dos cafeicultores locais na medida em que, nele, encontravam (ou podiam através dele encontrar mais facilmente) algo distante da realidade dos outros: um emprego capaz de lhes remunerar de modo muito expressivo.
Seus pais eram reconhecidos localmente por ter lhes propiciado as condições para que pudessem "progredir" no sistema educacional (como a construção de uma casa numa cidade onde frequentariam o Ensino Superior). Eles formavam uma espécie de elite de "médios" produtores frente a uma maioria de "pequenos" agricultores e trabalhadores rurais. Pareciam ser menos afetados pelo problema da fragmentação familiar das chacras, o qual, como mencionado entes, era agravado por conta do esgotamento dos solos e pelo envelhecimento dos cafezais. Entretanto, era comum escutar não só de seus filhos como também de outros jovens locais menos afortunados um discurso de gratidão muitas vezes comovente. Se os filhos nem sempre conseguiam ascender a uma posição social desejada por seus pais, quase sempre se viam em dívida para com os sacrifícios que eles realizaram em prol de seu bem estar.

Mas essa gratidão não se restringia às suas falas. Eles retribuíam os esforços de seus pais das mais variadas formas. Aqueles mais afortunados, como um dentista, engenheiro ou advogado, pareciam conduzir essa restituição concedendo aos seus pais um prestígio ou reconhecimento local. Isso também se dava com os que ocupavam os cargos mais graduados nas cooperativas de cafeicultores, apesar de que, tanto eles quanto seus colegas de trabalho, igualmente filhos de produtores de café, encararem seus empregos como uma atividade diretamente relacionada ao bem estar

35. Alguns sócios mais velhos, que participaram da fundação e/ou da "refundação" da cooperativa, costumavam dizer que a criaram ou a recriaram "para seus filhos" ou "pensando no futuro de seus filhos". Tal "refundação" se deu no final dos anos de 1990, logo após o fim de um conflito que assolou o país, mas algumas regiões de maneira especial, como foi o caso da selva central e o qual envolveu, de um lado, as Forças Armadas e, de outro, movimentos guerrilheiros de extrema-esquerda. A história desse conflito, da perspectiva dos agricultores ligados à La Florida, é retratada em Cruz (2010). 
de seus familiares, caso fossem funcionários de uma cooperativa à qual os últimos estivessem associados. Outra forma de se manterem vinculados aos progenitores era permanecendo junto aos seus cafezais e os "ajudando" nas tarefas ligadas ao dia a dia das plantações. Muitos, inclusive, voltavam de suas temporadas nas cidades para "auxiliá-los”. Os trabalhos que realizavam fora das suas propriedades rurais também podiam se converter num tipo de "ajuda" ou "auxílio" aos seus pais, na medida em que era comum darem a eles um montante dos recursos auferidos com essas atividades ${ }^{36}$.

Meu contato, em 2014, com aqueles, entre os filhos dos agricultores que estavam em melhor situação financeira, foi com os que eram ou haviam sido funcionários das cooperativas locais e que tinham frequentado o Ensino Superior. Colocados diante do dilema de ter que escolher entre "ganhar mais" comercializando café “por conta própria” ou continuar empregados nessas entidades e, dessa maneira, seguir num trabalho mais bem avaliado pelos produtores do que o chamado "comércio privado", uma grande parte deles decidira pelo primeiro caminho ou estava em vias de tomá-lo, apesar de que não enxergavam estas duas alternativas como mutuamente excludentes. Mas entre os que se mantinham nestas organizações como seus gerentes, por exemplo, era também comum existir um desejo de, através delas, acumular capital político para se lançarem como candidatos para algum cargo público.

Em suas falas ficava evidente o conflito que viviam entre querer proporcionar uma condição de vida melhor aos seus familiares e usar suas influências e habilidades em prol do bem estar dos cafeicultores ou dos cidadãos locais ${ }^{37}$. Porém, a desconfiança que os agricultores frequentemente demonstravam em relação às pessoas que se colocavam como seus intermediários comerciais e políticos criava um clima de insegurança entre os gerentes das cooperativas e que parecia contribuir para que se inclinassem em direção aos seus interesses mais particulares, o que não implicava em qualquer tipo de "individualismo", na medida em que o "indivíduo" e suas vontades eram encarados como aquilo por trás da ruína moral de alguém ${ }^{38}$.

Tal visão "anti-individualista" transparece, por exemplo, no relato de um, outrora, "fracassado" cafeicultor local a respeito de sua vida. Ele chegou à selva central no ano de 1965, junto de dois irmãos mais velhos. Trabalhou na colheita de café durante alguns anos e, em seguida, adquiriu sua propriedade. Segundo suas palavras, com o tempo, passou a "se dedicar à bebida" (cerveja), um "vício", no seu entender, e o qual

36. Esse era o caso, por exemplo, de um filho de um cafeicultor que recebeu de seu pai um automóvel para transportar os produtores até as cidades mais próximas. Ele entregava a este último, todos os dias nos quais trabalhava, uma porcentagem de seus lucros diários.

37. Um destes gerentes publicou o seguinte comentário na sua "página" de uma rede social da internet: "Trabalhar e trabalhar, pensando na família, na sociedade, sempre com muito esmero e dedicação, obrigado a Deus por me dar saúde e a minha família pelo grande apoio que ela me oferece".

38. Assim, nesse local, havia um sentimento generalizado de desconfiança tanto em relação ao que pode ser definido como um "mundo (social) exterior" (representado, sobretudo, pelos intermediários comerciais e políticos), que viveria à custa do trabalho dos agricultores, quanto em relação a um "mundo (psicológico) interior" (representado pelas vontades e desejos individuais). 
caminhava lado a lado com sua participação frequente em “festas". Essa trajetória errante teria consumido 30\% da sua renda anual e o levado ao "fracasso". 0 desrespeito mútuo tomou conta de sua família. Tal situação infeliz só fora revertida, afırmou ele, depois que viu um de seus filhos, então doente, "ser curado através do Evangelho". "Agora em casa há respeito e disciplina", me disse e completou: "Não tenho mais que me preocupar com meus filhos, sei que estão fazendo o bem, (...) estou há quatro anos convertido à Igreja Evangélica. Há um ano paguei minhas dívidas”. De acordo com ele, essas obrigações financeiras foram quitadas com o dinheiro que economizou ao deixar de contratar pessoas para trabalhar no seu cafezal e se apoiar na mão de obra de seus familiares: "Meus filhos colaboraram e agora recebem dinheiro para os estudos superiores; um deles (inclusive) não trabalha, só se dedica aos estudos, (...) em outros lares os filhos só trabalham (nas chacras de seus pais) se recebem”.
Essa narrativa autobiográfica está inserida num universo conceitual ou simbólico no qual a "união familiar" é encarada como algo construído, em boa medida, por meio das relações de interdependência entre os trabalhos de seus membros, sejam eles realizados dentro ou fora das propriedades rurais. A "bebida” (alcoólica) aparece aí como símbolo, por excelência, do mal, isto é, da desunião familiar, dado que tende a desviar as pessoas que a consomem dos deveres do trabalho ${ }^{39}$. Conforme assinalado antes, seu consumo, principalmente quando for "exagerado”, deve se dar de maneira eventual e coletiva, numa espécie de ritual normalmente realizado aos sábados à noite. É nesse horário e dia que costumam ocorrer, por exemplo, as festas de aniversário das cooperativas e quando os bares e prostíbulos da região estão cheios, confıgurando uma fase liminar em que o indivíduo emerge enquanto figura social legítima ${ }^{40}$. Trata-se, para se utilizar de uma expressão do antropólogo Victor Turner (1974), de um período

39. Lembro o caso de um produtor local (de origem andina) que, criticado pelos seus familiares por seu suposto hábito de consumir bebidas alcoólicas, lhes disse que "tinha o direito de aproveitar a vida", pois havia cumprido com seus deveres, isto é, "tido sucesso no trabalho" ao proporcionar aos seus descendentes as condições para que cursassem o Ensino Superior e deixado a eles propriedades no campo e na cidade. Sua esposa, segundo me contou um dos seus filhos, teria ficado extremamente irritada com um vizinho indigena que a aconselhou a "aproveitar mais a vida”, o que, na ocasião, significava se juntar a ele e ao seu marido enquanto os dois bebiam cerveja. Esse filho do casal afirmou que seu pai "sempre priorizou a educação de seus filhos, ao contrário da maioria dos produtores ao seu redor, hoje arruinados por terem se dedicado em demasia à diversão e ao álcool”. De qualquer maneira, esse jovem se mostrava bastante preocupado com o que via como "o problema de seu pai com a bebida" e junto de seus irmãos chegou a procurar ajuda médica para "resolver" essa questão.

40. Participando de uma festa de formatura dos alunos de um colégio local, fui advertido, pelo filho de um cafeicultor, de que não deveria dançar nesse evento, caso não consumisse bebida alcoólica. "As pessoas não vão ver com bons olhos você dançando sóbrio", me disse. No começo da festa, todos se mostravam acanhados e desconfortáveis; porém, com o passar do tempo, e com a ingestão generalizada e intensa de bebidas alcoólicas, por homens e mulheres, inclusive menores de idade, eles foram "se soltando" e "enchendo a pista de dança” até ela ser praticamente tomada. 0 álcool parecia cumprir o papel de legitimar a expressão pública de sentimentos de prazer e alegria que normalmente deveriam ser contidos ou renunciados, tendo em vista as exigências de uma vida cotidiana pautada pelo trabalho enquanto uma atividade que ganhava sentido principalmente em contraposição a estes sentimentos. 
onde parece existir um sentimento generalizado de communitas ou comunhão entre pessoas, notadamente do sexo masculino, que fora desse contexto se encontram absorvidas pelo mundo do trabalho e pelas relações sociais de cunho familiar ${ }^{41}$.

\section{Considerações finais}

Um dos principais sonhos dos mais abastados filhos dos cafeicultores que conheci (aqueles responsáveis pela intermediação do contato local com os novos mercados de café) era ter recursos suficientes para poder arcar com os custos de manter seus filhos, atualmente ainda bastante jovens, numa boa universidade europeia ou norte-americana. Diziam "trabalhar duro" para, um dia, ver esse desejo concretizado. Conscientemente ou não, estavam, assim como seus pais, ao privilegiarem com tanta força o trabalho, colocando sobre os ombros de seus descendentes o peso de uma vida dedicada a eles. De acordo com o que afırmavam, aparentemente não passava pelas suas cabeças qualquer intenção de diminuir seu ritmo de trabalho ${ }^{42}$. Isso porque essa atividade não tinha como objetivo exclusivo a acumulação material, como parece pressupor Shoemaker (1981), num dos poucos estudos etnográficos sobre os cafeicultores da selva central, conforme já fora assinalado anteriormente neste artigo. 0 trabalho ocupa um lugar central em suas vidas sociais não porque é através dele que esses sujeitos e seus filhos podem garantir sua "subsistência" ou "progredir", e sim porque essa atividade expressa ou simboli$z a$ o que consideram como o cerne de suas existências - a família. Shoemaker não foi capaz de ver o tanto de sentido e, consequentemente, de socialidade, que se encontram presentes no trabalho desempenhado por estas pessoas. Ele acaba se pautando pela visão desses agentes sobre a ausência de um "progresso" local enquanto uma situação que se apoiaria na inexistência de um destino comum mais amplo sentido entre eles ${ }^{43}$.

Mas a preocupação com o que falta num universo social pode se colocar como um dos principais obstáculos para se entender

41. De uma perspectiva estruturalista, é possível dizer que as relações sociais locais se organizam com base numa estrutura simbólica na qual o trabalho se opõe ao lazer, assim como a família se opõe ao indivíduo, assim como a cultura se opõe à natureza (trabalho/lazer: família/indivíduo: cultura/natureza) e onde as bebidas alcoólicas se colocam como as principais formas de mediação, de passagem ou de mudança entre o trabalho e o lazer, entre a família e o indivíduo e entre a cultura e a natureza (humana, no caso).

42. Segundo um filho de cafeicultores locais, "muita felicidade ou muita alegria implica no livre arbítrio, em não ter limites e isso é perigoso porque você se esquece de Deus e dos outros. Muita felicidade é algo demoníaco, você se esquece da parte espiritual e familiar. Só a felicidade momentânea é boa. A vida é dura, é uma luta diária”. Conforme se vê, através de sua fala, a oposição entre trabalho e lazer pode também se relacionar com a oposição entre Deus e o diabo.

43. Refletindo sobre os moradores de Satipo, uma das províncias da selva central, Shoemaker (1981) conclui: "sem nenhum veículo para a expressão e a busca de objetivos de classe, a maior parte dos habitantes de Satipo permanecerá onde esta hoje: no caminho da sobrevivência diária." (idem p. 171) No seu livro intitulado Tropical Colonization: The case of Chanchamayo and Satipo in Peru, Peter Sjoholt (1988) analisa uma série de dados quantitativos referentes a duas províncias da selva central (Chanchamayo e Satipo) e que foram coletados em meados de 1981. A partir de um questionário aplicado a 60 famílias de uma comunidade local dessa região, esse autor afirma que uma das principais queixas feitas por seus informantes era a da "falta de solidariedade entre os colonos." 
como os sujeitos que dele participam concebem o que é uma relação social e o quê é capaz de produzi-la. Os colonos andinos, ao migrarem para a selva central, tendo em vista o exercício de um trabalho que pudesse garantir aos seus filhos uma vida melhor, se viram, em grande parte, frustrados diante da incapacidade de alcançarem esse objetivo. Entretanto, essa frustração, também compartilhada, de certo modo, pelos indígenas ao seu redor, não pressupõe, necessariamente, uma carência ou ausência de relações sociais - de acordo com a perspectiva dos moradores locais - na medida em que a forma culturalmente dominante dessas relações entre eles, no caso, a relação entre pais e filhos, pode ser mantida independentemente do acúmulo de bens e capitais. Mesmo os poucos que conseguiram ascender a uma vida mais confortável economicamente sabem que essa situação não garante automaticamente uma posição moral superior. Isso porque nesse cenário "quem tem muito (dinheiro) e (supostamente) não trabalha” é comumente associado com a figura do bandido ou ladrão, duas “categorias de xingamento" bastante utilizadas nesse espaço, assim como as de bêbado, vagabundo e ocioso.

0 trabalho no campo, como o paradigma, por excelência, do trabalho, se pauta pela ideia de que a essência dele esta no suor dos que se dedicam a ele com afınco, e esse suor parece ser encarado localmente como o principal ingrediente responsável por manter as famílias unidas. Em suma, a desvalorização econômica da agricultura local não deve nos cegar para o papel do trabalho familiar rural como fonte do simbolismo que orienta as ações dessas pessoas, independentemente de estarem ou não exercendo algum ofício notadamente agrícola, pois de onde mais extrairiam os referenciais para se pensar a interdependência entre pais e filhos através do trabalho ${ }^{44}$

44. Em se tratando de um espaço onde a produção agrícola gira, de certo modo, em torno da família, não é de se estranhar que o trabalho caracterize esta unidade social. Entretanto, nesse local, as relações de interdependência entre pais e filhos, pensadas através do trabalho, fazem sentido dentro de um arcabouço conceitual que, apesar de, aparentemente, tomar como referencial a agricultura de caráter familiar, não deriva, diretamente, de uma situação de interdependência econômica entre essas pessoas. A concepção de uma dependência material mútua entre pais e filhos é uma consequência, e não causa, de um universo social e semântico onde o trabalho e as relações familiares se cofundem, ao contrário do que acontece na "cultura ocidental", por exemplo, na qual o trabalho tende a ser associado ao indivíduo e dissociado da família, conforme assinala Marshall Sahlins (2003). Não é sem razão que nesse último universo cultural o trabalho também apareça como uma atividade associada à satisfação das necessidades ou desejos individuais e as relações sociais como extrínsecas aos "trabalhadores". 


\section{Referências}

BERG, R. The effects of return migration on a highland peruvian community. Phd. Thesis. University of Michigan, 1984.

CADENA, M. Indigenous mestizos: the politics of race and culture in Cuzco, Peru, 1919-1991. Durham: Duke University Press, 2000.

CLASTRES, P. Arqueologia da violência. São Paulo: Cosac e Naify, 2004.

CONTRERAS, C. \& CUETO, M. Historia del Perú Contemporáneo. Lima: IEP, 2004.

CRUZ, R. Sagas do "comércio justo" e percepções da modernidade na selva central peruana. Rio de Janeiro, 2010. Tese (Doutorado) - Programa de Pós Graduação em Antropologia Social do Museu Nacional, Universidade Federal do Rio de Janeiro. 2010.

DEGREGORI, C. El surgimiento de Sendero luminoso. Lima: IEP, 1990.

DESCO. Perú Hoy, La desigualdad en el Perú. Desco: Lima, 2005.

DURAND, F. El poder incierto: trayectoria económica del empresariado peruano. Lima: Fondo Editorial del Congreso del Perú, 2004.

MACFARLANE, A. A cultura do capitalismo. Rio de Janeiro: Zahar, 1989.

MAYER, E. Casa, chacra y dinero. Economias domesticas y ecologia en los Andes. Lima: IEP, 2004.

ORTNER, S. Teoria na antropologia desde os anos 60. Mana, v. 17, n² 2, p. 419-466, 2011.

OSSIO ACUÑA, J. Parentesco, reciprocidad y jerarquia en los Andes. Lima: Fondo Editorial de la Pontificia Universidad Católica del Perú, 1992.

SANTOS, F.; BARCLAY, F. Ordenes y desórdenes en la Selva Central: historia y economia de un espacio regional. Lima: IEP, 1995.

SANTOS, F. Guía Etnográfica de la Alta Amazonía. Lima: IFEA, 2004.
SAHLINS, M. Cultura e Razão Prática. Rio de Janeiro: Zahar, 2003.

SHOEMAKER, R. The Peasants of El Dorado. New York, Cornell University Press, 1981.

SJOHOLT, P. Tropical colonization: the case of Chanchamayo and Satipo in Peru. Stockhom: Institute of Latin American Studies, 1988.

SKAR, S. Lives Together - Worlds Apart: Quechua Colonization in Jungle and City. Oslo: Scandinavian Universty Press, 1994.

TURNER, V. 0 processo ritual. Petrópolis: Vozes, 1974.

WOORTMAN, K. “Com parente não se neguceia”: o campesinato como ordem moral. Anuário Antropológico, nº 87, p. 11-73, 1990. 


\section{RESUMO}

Este texto se debruça sobre a experiência social do trabalho a partir da perspectiva das famílias dos agricultores de uma zona rural da selva central peruana. Estes sujeitos se definem como "pequenos" ou "médios" produtores de café, apesar de ser comum, entre os que possuem as menores lavouras, o trabalho temporário ou eventual num cafezal alheio. A maioria é formada por "colonos" vindos dos Andes e por seus descendentes. Uma minoria é composta por indígenas "nativos" da Amazônia. Trata-se aqui de entender, num primeiro momento, as condições sociais do trabalho local como produtor de café e, em seguida, as relações das trajetórias das gerações mais velhas de cafeicultores com as mais variadas atividades remuneradas que seus filhos vêm exercendo dentro e fora da selva central. Tais atividades se dão num contexto marcado, em especial, pela "decadência" da agricultura, pelo predomínio de empregos "informais" e "precários", pelo "auto-emprego" ou "empreendedorismo" e pela valorização cada vez maior de profissões que demandam, para o seu exercício, a posse de um diploma ou certificado de Ensino Superior.

\section{PALAVRAS-CHAVE}

Trabalho. Família. Agricultura.

Amazônia. Peru.

\section{ABSTRACT}

This text focuses its attention on the social experience of work from the point of view of the families of farmers from a rural zone in the Peruvian central jungle. These subjects define themselves as "small" or "medium" coffee growers, despite its common, among those who own the smallest portions of land, the temporary or casual work in someone's coffee plantation. The majority of them is formed by "settlers" coming from the Peruvian Andes and their descendants. A minority is composed of indigenous peoples "natives" of the Amazon jungle. It's intended here to understand, first, the social conditions of their dedication to the coffee growing and, subsequently, the relations of the trajectories of the older generations of coffee growers with the most diverse remunerated activities which their sons have been practicing inside and outside the central jungle. Those activities exist in a context marked, in particular, by the "decadence" of the agriculture, by the preponderance of "informal" and "precarious" jobs, by the tendency for "self-employment" or "entrepreneurship" and by the increasing acknowledgement of "professions" that demands, for its exercise, the ownership of a college diploma or certificate.

\section{KEYWORDS}

Labor. Family. Agriculture. Amazon rainforest. Peru. 